\title{
DIRSTASIS OF THE PUBIC SYMPHYSIS WITH SPECIAL CONSIDERATION OF PREGNANCY AND PARTURITION
}

\author{
GAIL WILSON B.Sc. (Physio.) Witwatersrand
}

The human symphysis pubis undergoes a variety of hanges under the influence of age and function, and female, under the special hormonal influence of in the female the mechanical trauma of parturition. pregnancy a synchondrosis which usually changes into It starts as a sis and occasionally develops into a real a hemiarthrosint. At birth, the connection between the diarthrodial is uninterrupted, consisting posteriorly and pubic bon of cartilage, anteriorly and inferiorly of superiorly of ligamentous connective tissue. The median vascularized ligavelop in the second year of life, and cleft begins to with the increased shearing stresses on the this coincide to the assumption of the upright gait. s)mphysis durvey, (Putschar, 1971) $97 \%$ of adult females howed these primary clefts.

Secondary traumatic clefts in the cartilage are more frequent in females, due to ovarian and placental hormones in pregnancy. Relaxin has a remarkable effect on collagen tissues, causing hypertrophy of the individual cells. It is most marked where collagen cells re very tightly packed together, e.g. in the dense ligaments of the pelvis. These effects occur within hours of the administration of relaxin (Van Rooyen, 1974). Oestrogen, progesterone, pregnenolone, pregnandiol and other hormones have the same effect, but take longer to produce the changes. Delivery of a mature infant produces traumatic changes in the symphysis pubis, leading to extrusion of torn fibrocartilage in any pre-existing cleft, so that complete clefts are much more common in females after parturition. The margins of these various cartilage tears undergo degenerative changes and, although the haemorrhage is resorbed, the cartilage tears do not heal. In multiparous women, one observes additional tears from the most recent pregnancy, superimposed an old unhealed tears and each pregnancy and delivery leaves the pubic symphysis permanently somewhat loosened.

A roentgenographic survey (Vix, 1971) showed an average width of $7,1 \mathrm{~mm}$ in a large number of pregnant subjects, compared to an average of $4,1 \mathrm{~mm}$ in nonżregnant women.

(

\section{RESULTS OF A LOCAL STUDY}

The following table indicates the incidence of this problem in a local study of 409 patients seen regularly during the last trimester of pregnancy.

Total number of Pregnancies

Total

Number \%

$409 \quad 100$

Primigravida

$318-77,8$

Para 1

$79-19,3$

Para $2+$

2,9

$16 \quad 3,9$

$7 \quad 2,2$

$8 \quad 10,1$

Primigrav. with Pubic Symph. Prob.

Para. 1 with Pubic Symph. Prob.

Para. $2+$ with Pubic Symph. Prob.

These results confirm the earlier discussion. Of the patients seen $3,9 \%$ had pubic symphysis problems; the primigravida has a $2,2 \%$ incidence and the multipara showed a much higher incidence. Of the patients complaining of pubic symphysis problems $56 \%$ were multiparous women.

\section{SIGNS AND SYMPTOMS OF PUBIC SYMPHYSIS PROBLEM}

\section{Pregnancy}

Age seemed to have no bearing on the situation. On average, the signs and symptoms were noted from the 30 th week of pregnancy. They were most marked between 34 - 36 weeks, a stage at which the hormonal level is presumably very high. At this stage in some primigravida traumatic damage may arise as the head engages in the pelvic inlet. Some multiparous patients reported problems starting at 24 weeks or even earlier.

Pain was localised at the symphysis pubis. Aching occurred in the groin either bilaterally or unilaterally. These symptoms were reproduced by passive mobilisation of the symphysis pubis, by resisted trunk flexion and by pressure on the iliac crests which forced them laterally. All patients complained of extreme stiffness and pain in the groin and of difficulty with ambulation following bedrest. Prolonged standing, walking and weight transferance, e.g. stepping off a kerb, caused pain. In severe cases a waddling gait developed. Exercises in the ante-natal class involving abduction of the hip, often provided the first indication that the problem was arising; the patient experienced pain and was unable to carry out the exercise.

In some subjects there was associated pain over the sacro-iliac joints, without the disabling symptoms described above.

\section{Puerperium}

Two cases, both following the birth of their second baby, who had not received any ante-natal therapy, were referred for treatment on the 3rd day post partum. The diagnosis of diastasis of the symphysis pubis was made as ambulation had become impossible. These were the most severe cases in the study, and also took the longest time to rehabilitate. Marked pain was present over the pubic symphysis, pain was experienced on trunk movements and they were unable to attempt straight leg raising. Transference of weight, as in a normal gait pattern, was initially severely limited by pain.

\section{TREATMENT}

\section{Pregnancy}

Obstetric textbooks advocate bedrest and a supporting binder for patients exhibiting this condition. Experience with these cases indicated that bedrest produced more pain, stiffness and gross immobility. An exercise programme, mobilisation and the wearing of a maternity corset for the binding effect produced good results.

Treatment was as follows:

As soon as signs and symptoms of loosening of the pubic symphysis were noted, the patients were given an exercise routine similar to that used in a back class, but obviously these exercises did not involve any strong trunk flexion or hip abduction which would aggravate the separation of the symphysis pubis. Leg movements using patterns of hip flexion, adduction and internal rotation with knee flexion were also used. 
In mild cases this exercise programme provided relief from the stiffness. Patients who missed ante-natal physiotherapy sessions or had been confined to bed for other medical reasons, immediately reported marked stiffness and pajn on ambulation. Those patients who were improving and were overkeen and did an excessive amount of walking or standing also presented with more pain.

The more severe cases, mostly multiparous mothers, followed an adapted exercise programme. They required local heat, e.g. infra-red prior to the mobilisation procedures which gave marked relief of pain. The mobilisation was done with the patient in the supine position. The therapist flexed the hip and knee, interlocked the fingers of both hands and cupped them over the top of the knee. The hip was then adducted and internally rotated, with as much flexion as the pregnant uterus will allow (Maitland 1977). An oscillating downward force was then applied, working short of the pain initially. The dosage of mobilisation depended on the severity of the pain. The procedure was initially carried out on the most painful side and then on the opposite side. The side exhibiting the most pain and resistance can be likened to a tight bow-string. Relief from the pain and stiffness followed this mobilising procedure and ambulation and movement became easier. A maternity corset was advocated for the binding effect to approximate the symphysial ends and was used for prolonged walking or standing. Adduction of the thighs was also encouraged to correct the waddling gait.

\section{Post-parturition}

Great care must be taken when treating these patients as post-partum avulsion can occur very easily up to the tenth day. The reason for possible symphysial avulsion is the result of the rapid fall in the hormone levels, causing anoxic changes in the collagen fibres due to thromboses, and the symphysial ligament is extremely weakened. Strong trunk flexion is contra-indicated as this can increase the symphysial width by up to $7,1 \mathrm{~mm}$ and the sudden strong muscular action of trunk flexion can result in a total tear of the symphysial ligament and total separation of the pubic symphysis (Van Rooyen, 1974).

Bearing these points in mind, an exercise plan for mobility was given, avoiding prone kneeling positions which could lead to air embolus. Mobilisation procedures and infra-red irradiation were also used. A tight corset or binder was then applied to facilitate walking. Patients gradually improved over the first six weeks, after which they joined a post-natal exercise group where trunk flexion and hip abduction were slowly progressed.

\section{RESULTS}

Two to three months post-partum the patients were pain-free and able to do all the exercises. One case re-injured three months after her delivery due to a fall on a tennis court. She presented with a chronic symphysiolysis and improved gradually on regular exercise treatment. Orthopaedic advice was to continue prolonged conservative treatment. The use of hydrocortisone injection, as mentioned in some of the literature (Sharp, 1973) was not suggested in any of the cases, and open reduction with plate fixation, as for disrupted pubic symphysis resulting from traumatic injuries, obviously did not apply in these cases.

\section{References}

1. Maitland, G. D. (1977): Vertebral Manipulation, 4th ed. Butterworths, London.

2. Putschar, W. G. J. (1976): The Structure of the Human Symphysis Pubis with Special Consideratiof of Parturition and its Sequelae. Am. J. of Phys Anthropol., 45, 589 - 594.

3. Sharp, I. K. (1973): Plate Fixation of Disrupted Symphysis. J. Bone Joint Surg., 55 (B), 618-620.

4. Van Rooyen, A. J. L. (1974): Pelvic Joint Movements in Pregnancy. Paper read to S.A.S.P. Obstetric Association Symposium.

5. Vix, V. A. and Ryu, C Y. (1971): The Adult Symphysis Pubis: Normal and Abnormal. Am. J. Roentgenol Radium Ther. Nucl. Med., 112, 517-525.

\section{Bibliography}

1. Harris, N. H. (1974): Lesions of Pubic Symphysis in Women. Brit. Med. J., 4, 209 - 211.

2 Hawkins, D. F. (1974): Obstetric Therapeutics, 1st Ed. Bailliere Tindall, London.

3. Lewis, M. M. (1977): Pubic Symphysis Diastasis treated by. Open Reduction and Internal Fixation. Clin. Orthop., 123, 37 - 39.

4. Maitland, G. D. (1970): Peripheral Manipulation, 1st Ed. Butterworths, London.

5. Olerud, S. and Grevsten, S. (1974): Chronic Pubis Symphysiolysis. J. Bone Joint Surg., 56A, 799-802.

6. Rovinsky, J. J. and Guttmacher, A. F. (1971): Medical, Surgical and Gynecologic Complications of Pregnancy. 2nd Ed. Williams and Wilkins, Baltimore. (1)

7. Wah, L. M. (1977): Effect of Hormones on Collagerf Metabolism and Collagenase Activity in the pubic symphysis ligamen of the guinea pig. Endocrinology, vl 100, 571 - 5799.

\section{DIVISION OF CONTINUING MEDICAL EDUCATION}

\section{UNIVERSITY OF THE WITWATERSRAND}

Tel.: $725-2915 / 75$

1 - 3 March 1979: Civil Defence Conference and Workshop.

7 March 1979: Financial Management.

9 10 March 1979: Learning about Terminal Care.

17 March 1979: The Mentally Handicapped Pre-school Child.

9 - 13 July 1979: Learning Disabilities.

\section{JOURNAL OLD COPIES}

The Editorial Board plans to bind two sets of back copies of the Journal and need the following issues to complete the two sets:

March, July and October 1949.

April, July and October 1950.

April 1951.

January and October 1952.

January and July 1953.

April 1954.

March 1960.

December 1968.

June 1974. 